\title{
Os sentidos do trabalho para enfermeiras no cotidiano da profissão
}

RESUMO | Objetivo: Identificar quais os sentidos do trabalho atribuídos às enfermeiras em suas rotinas diárias de atuação. Método: A abordagem do estudo apresentou-se de forma qualitativa e, a coleta de dados, procedeu mediante entrevistas individuais com nove participantes no período de abril de 2019. As categorias de análise foram compostas no eixo dos sentidos do trabalho e seus seis constructos (utilidade social, oportunidades de aprendizagem e desenvolvimento, autonomia, cooperação e relacionamento com os demais colaboradores). Resultados: Os seis constructos foram identificados e correlacionados com a rotina de trabalho de cada profissional. Os resultados indicaram que o sentido do trabalho para cada profissional possui características polissêmicas e, muitas vezes, confrontantes. Conclusão: Esta pesquisa contribui com as discussões a respeito da sensibilização dos profissionais enfermeiros quanto aos sentidos do trabalho e a essência do cuidado à profissão.

Descritores: Educação Permanente em Saúde; Sentidos do Trabalho; Enfermagem.

ABSTRACT | Objective: Identify the meanings of work attributed to nurses in their daily work routines. Methodology: The study approach was presented in a qualitative way and data collection proceeded through individual interviews with nine participants. The analysis categories were composed in the work senses axis and its six constructs (social utility, learning and development opportunities, autonomy, cooperation and relationship with other employees). Results: The six constructs were identified and correlated with the work routine of each professional. The results indicated that the meaning of work for each professional has polysemic and often confronting characteristics. Considerations: This research contributes to discussions regarding the awareness of professional nurses about the meanings of work and the essence of care for the profession.

Keywords: Continuing Health Education; Directions of Work; Nursing

RESUMEN | Objectivo: Identificar los significados del trabajo atribuidos al enfermero en sus rutinas laborales diarias. Metodología: El enfoque del estudio se presentó de forma cualitativa y la recolección de datos se realizó a través de entrevistas individuales con nueve participantes. Las categorías de análisis se compusieron en el eje sentidos del trabajo y sus seis constructos (utilidad social, oportunidades de aprendizaje y desarrollo, autonomía, cooperación y relación con otros empleados). Resultados: Se identificaron los seis constructos y se correlacionaron con la rutina de trabajo de cada profesional. Los resultados indicaron que el significado del trabajo para cada profesional tiene características polisémicas y muchas veces enfrentadas. Consideraciones: Esta investigación contribuye a las discusiones sobre la conciencia de los profesionales de enfermería sobre los significados del trabajo y la esencia del cuidado para la profesión.

Palabras claves: Educación Continuada en Salud; Direcciones de trabajo; Enfermería.

Ana Claudia Delfini Capistrano de Oliveira

Doutora em Sociologia Política, Docente, Itajaí (SC).

ORCID: 0000-0002-7154-9020

\section{Mayara Ana da Cunha Kersten}

Doutora em Educação, Docente, Itajaí (SC). ORCID: 0000-0002-6460-5207

\section{Rafaella Rebello}

Mestre em Educação, Enfermeira, Docente, Coordenadora do Eixo Saúde do Serviço Nacional de Aprendizagem Comercial (SE$\mathrm{NAC}$ ), Itajaí (SC).

ORCID: 0000-0002-8684-5981

\section{Sandy Aparecida Pereira}

Doutoranda em Educação, Docente, Porto Belo (SC).

ORCID: 0000-0001-7504-6765

\section{Tania Regina Raitz}

Doutora em Educação, Docente, Itajaí (SC). ORCID: 0000-0002-4698-6077

Recebido em: 10/12/2021

Aprovado em: 07/01/2022

\section{INTRODUÇÃO}

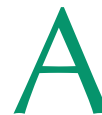
enfermagem é reconhecida como uma profissão da área da saúde que possui em sua essência o cuidado com o ser humano. Há múltiplas condições que envolvem o trabalho deste profissional, na qual uma abrangente área de atuação possibilita-lhe desenvolver suas competências e habilidades requeridas em diversos setores de saúde. Essas atribuições são alicerçadas nos eixos da assistência, ensino, pesquisa e gerência, previstas na Lei do Exercício Profissional $N^{0} 7.498$ de 25 de junho de $1986^{(1)}$.
Profundas transformações ocorreram no mercado de trabalho a partir do ano de 1990, especialmente pela nova metodologia da organização do mesmo, com a reestruturação produtiva e novos avanços tecnológicos, como por exemplo, cibernética, informatização e a internet. Tais mudanças são parte do processo de globalização, que provocaram novas exigências no perfil dos profissionais de diversas áreas e de suas práticas profissionais.

O trabalho, portanto, é "um processo que simultaneamente altera a natureza e autotransforma o próprio ser que trabalha"(2). O sentido do trabalho é "uma

Iprodução pessoal decorrente da apreensão individual dos significados 
coletivos, nas experiências cotidianas $^{\prime \prime(3)}$.Os sentidos do trabalho remetem aos diferentes valores e concepções sobre este. $\mathrm{Na}$ atualidade, os estudos sobre os sentidos do trabalho possuem uma abrangência multidisciplinar, sob diversos pontos de vista teóricos, num construto psicológico multidimensional, dinâmico e resultante da interação de variáveis distintas ${ }^{(4) . ~ H a ́ ~ s e i s ~ c o n s-~}$ tructos que determinam o sentido do trabalho $\left.^{(5)}: 1\right)$ utilidade social; 2) oportunidades de aprendizagem e desenvolvimento; 3) autonomia; 4) cooperação e relacionamento com colegas; 5) reconhecimento e; 6) retidão moral. Alguns autores ressaltam a possibilidade enriquecedora do estudo dos seis constructos dos sentidos do trabalho em outras áreas, o que reforça a necessidade de novos estudos, inclusive na área da Enfermagem ${ }^{(6)}$.

No cotidiano da enfermagem, podemos verificar estas dimensões dos seis constructos interagindo entre si e, considerando a relevância científica e social do trabalho da Enfermagem nos serviços de saúde. Sendo assim, a questão norteadora que embasou a pesquisa foi: qual o sentido do trabalho para as enfermeiras do hospital infantil?

\section{MÉTODOS}

Utilizou-se a metodologia qualitativa para analisar os sentidos do trabalho atribuídos por enfermeiras que atuavam em um hospital na região sul do Brasil, constituindo-se, portanto, de um estudo exploratório descritivo. A coleta de dados aconteceu mediante levantamento documental, aplicação de questionário para levantamento socioeconômico dos profissionais e entrevistas semi-estruturadas individuais com os participantes, acordadas entre estes e a instituição, através de uma escala prévia de agendamento. Foram observados os aspectos éticos da pesquisa envolvendo seres humanos, seguindo as
Os sentidos do trabalho remetem aos diferentes valores e concepções sobre este. $\mathrm{Na}$ atualidade, os estudos sobre os sentidos do trabalho possuem uma abrangência multidisciplinar, sob diversos pontos de vista teóricos, num construto psicológico multidimensional, dinâmico e resultante da interação de variáveis distintas. Há seis constructos que determinam $o$ sentido do trabalho orientações da Resolução n. 466/2012, do Conselho Nacional de Saúde e foi aprovado pelo Comitê de Ética em Pesquisa local (sob número 3.097.649, CAAE: 008113318.5.0000.0120).

Realizou-se a pesquisa num hospital infantil de referência na região da Foz do Rio Itajaí Açú, localizado na região sul do Brasil. Os critérios de inclusão dos entrevistados foram: todos os profissionais enfermeiros que trabalhavam na instituição por pelo menos um mês e, profissionais que não obedeceram a este tempo mínimo, não foram incluídos na pesquisa (critério de exclusão).

A definição das questões inclusas na entrevista sobre os sentidos do trabalho às Enfermeiras foram pré-determinadas com base nos seis constructos previamente descritos ${ }^{(5)}$ (utilidade social; oportunidades de aprendizagem e desenvolvimento; autonomia; cooperação e relacionamento com colegas; reconhecimento $\mathrm{e}$; retidão moral) e, partir de então, desenvolveuse um questionário com sete questões abertas, conforme a seguir: 01) O que é trabalho para você?; 02) Qual sua percepção em relação a utilidade do seu trabalho para as pessoas?; 03) O que marcou a sua vida em termos de oportunidades de aprendizagem no trabalho? Nos dê alguns exemplos. 04) Comente como você vê a sua autonomia no seu trabalho. 05) Como você vivencia a cooperação e o relacionamento com seus colegas de trabalho?; 06) Qual a sua percepção na questão do reconhecimento do seu trabalho?; 07) Como você vivencia as dimensões éticas no ambiente do seu trabalho?.

As entrevistas, realizadas pela pesquisadora responsável em Abril de 2019, abrangeu os turnos matutino, vespertino e noturno de trabalho e, foram conduzidas em locais apropriados dentro do próprio hospital. As identidades das enfermeiras foram preservadas e denominadas como E01 
(Enfermeira 01), E02 (Enfermeira 02) e, assim por diante. Consideramos pertinente a discussão dos sentidos do trabalho na fase pré pandemia de Covid-19, sendo uma das justificativas para submissão de tal estudo, possibilitando este contrastar com as realidades atuais e outros estudos na temática.

\section{RESULTADOS}

O hospital infantil na qual os profissionais atuavam realiza atendimentos para crianças de zero a quatorze anos pelo SUS, ou por convênios (privados e particulares) e, é classificado como uma instituição de médio porte, dispondo de 93 leitos para internação. No total, 17 profissionais da enfermagem atuavam no hospital em questão, nos setores: Unidade de atendimento A e B; centro cirúrgico; pronto socorro; unidade de terapia intensiva; comissão de controle de infecção hospitalar e; gerência de Enfermagem nos turnos matutino, vespertino e noturno. Após apresentação individual da pesquisa e do Termo de Consentimento Livre e Esclarecido (TCLE) e do Consentimento de Participação, nove profissionais aceitaram participar da pesquisa.

Os resultados indicaram um perfil socioeconômico dos profissionais com idade de até 40 anos $(n=6)$ (variando de 33 a 50 anos), gênero feminino $(\mathrm{n}=9)$, grande parte casada $(\mathrm{n}=6)$, autodenominação étnica branca $(n=6)$, residentes de Itajaí $(\mathrm{n}=5)$, com média de dois filhos que só estudavam. O perfil etário das enfermeiras entrevistadas em nossa pesquisa corrobora com a literatura (faixa etária de 30 a 40 anos) (7). A predominância de profissionais do gênero feminino está de acordo com o último banco de dados do Conselho Federal de Enfermagem, que identificou $86 \%$ dos profissionais do sexo feminino e, apenas $13 \%$, do sexo masculino(8), não distando, portanto, dos dados apresentados.

A predominância de profissionais recém-formados de nosso estudo corrobora com a literatura(9) (tempo de formação média de sete anos) e, a busca por especializações denotam a preocupação dos mesmos com $\mathrm{O}$ aperfeiçoamento de suas habilidades.

A presença de dois vínculos laborais foi marcante $(n=5)$ e, grande parte das entrevistadas possuía renda mensal de um a três salários mínimos $(n=4)$. De acordo com alguns autores, a presença de um segundo vínculo laboral justifica-se devido aos baixos níveis salariais e busca de melhores condições de vida(10). O perfil salarial das enfermeiras entrevistadas está em concordância com dados do IBGE, que apontam média salarial mensal de $\mathrm{R} \$ 2.649,00$ para profissionais dos setores de educação, saúde e serviços sociais $^{(11)}$.

\section{DISCUSSÃO}

Primeiro Constructo - Utilidade Social do Trabalho

Quando lançamos a pergunta "O que é trabalho para você?" a inquietação esteve presente, principalmente, na expressão corporal das enfermeiras. Em estudo envolvendo 14.700 indivíduos em oito países foram entrevistados e questionados com esta mesma pergunta e, as respostas geraram concepções positivas, negativas ou neutras (12). As ideias centrais das respostas de algumas enfermeiras entrevistadas contratadas de um hospital infantil localizado na região Sul do Brasil relativas à questão 01) "O que é trabalho para você?" são descritas abaixo:

[...] é uma atividade onde eu exerço algum, alguma forma de... como eu posso dizer... para solucionar uma questão, alguma situação. (E01)

[...] é conscientizar aquilo que a gente precisa no dia a dia com ética e respeito. (E03)

[...] trabalho é a prática de atividades tanto práticas e técnicas e principalmente quando a gente aprende na graduação do curso. (E05)

[...] trabalho em primeiro lugar é ocupação [...] não tem como adquirir alguma coisa se não tiver trabalhando. (E06)

[...] trabalho é uma responsabilidade [...] tem gente que pensa que é só o dinheiro. (E07)

[...] é a possibilidade que eu tenho de enriquecer meus conhecimentos, possibilidade que eu tenho de me relacionar com os outros [...] faz eu me sentir realizada profissionalmente né. (E09)

Os sentidos do trabalho mesclaramse na diversidade das falas: num mesmo sujeito aparecem diversos sentidos. $\mathrm{O}$ atributo do trabalho como uma atividade para sustento, sobrevivência e renda também esteve presente.

Neste cenário socioeconômico, onde as mulheres necessitam manterse em mais de um vínculo laboral para ter um acréscimo de renda, devemos questionar: Se esta categoria mantivesse bons salários, este viés de trabalho atrelado à renda existiria? Participantes de uma pesquisa(13) compreendem o trabalho por meio de seu aspecto instrumental e financeiro, sendo um dos primeiros aspectos apontados. No entanto, em estudo similar(14), a questão financeira foi mencionada por todos os participantes, sempre acompanhado de outro elemento complementar ao trabalho, porém, nenhum entrevistado relacionou a percepção de baixa remuneração à falta de sentido do trabalho.

As ideias centrais das respostas 
de algumas enfermeiras entrevistadas relativas à questão 02) "Qual sua percepção em relação a utilidade do seu trabalho para as pessoas?" são descritas abaixo:

[...] acho fundamental porque aqui a gente acolhe muito bem as crianças sendo um setor crítico de medo, insegurança [...] é a primeira vez que eu trabalho com criança e eu gosto muito, estou até pensando em fazer pediatria. (E01)

[...]é bem importante em relação não só para a equipe e mais para os pacientes, eles estão aqui porque precisam e tenho que dar o melhor de mim sempre. (E04)

[...] o gerenciamento sim, no gerenciamento da unidade, esta questão de gerenciamento de leitos principalmente. (E05)

[...] não sei responder. (E06)

[...] a utilidade do meu trabaIho na minha percepção para as pessoas é em prol do bem estar delas, tanto individual como coletivo [...] no sentido mais amplo a gente vai além do cuidado da saúde né, a gente cuida da pessoa. (E09)

As enfermeiras entrevistadas em nosso estudo definem o constructo "Utilidade Social do Trabalho" como importante, com desdobramentos na humanização, acolhimento e reconhecimento. A recuperação, proteção, prevenção e o bem estar proporcionado para cada paciente atendido é mencionado claramente pela resposta da E09.

Segundo Constructo - Oportunidades de Aprendizagem e Desenvolvimento

A aprendizagemeodesenvolvimento
[...] a dor das

mães me marca

muito, quando elas chegam aqui com a criança bem ruim, aquele semblante, eu não sei nem colocar as palavras, pedindo socorro no olhar e depois saindo daqui com aquele sorriso e agradecimento, isso é muito gratificante, marca a vida da gente. (EO3) são apresentados por alguns autores(14) como importantes na dimensão individual na construção dos sentidos do trabalho e, que, um trabalho sem sentido não explora o potencial e não há crescimento de quem o exerce. As ideias centrais das respostas das nove enfermeiras entrevistadas relativas à questão 03) "O que marcou a sua vida em termos de oportunidades de aprendizagem no trabalho? Nos dê alguns exemplos." são descritas abaixo as falas mais marcantes de algumas enfermeiras:

[...]eu sempre tive que buscar né, nada veio assim e nem oferecido sabe, eu acho que agora as oportunidades são melhores que antes, quando eu me formei [...] não tinha esta gama de pós-graduação que se tem hoje. (E01)

[...] quando eu me formei vim de outro estado para cá justamente para trabalhar e comecei a trabaIhar no resgate [...] eu trabalhei 10 anos neste resgate então para mim foi um aprendizado. (E02)

[...] a dor das mães me marca muito, quando elas chegam aqui com a criança bem ruim, aquele semblante, eu não sei nem colocar as palavras, pedindo socorro no olhar e depois saindo daqui com aquele sorriso e agradecimento, isso é muito gratificante, marca a vida da gente. (E03)

[...] como enfermeira é meu primeiro trabalho. O que marcou na outra instituição que eu trabalhava (como técnica de Enfermagem) tinha muita educação continuada. (E05)

[...] hoje eu sou Enfermeira mas eu já fui técnica de Enfermagem há 20 anos. Então quando eu comecei a minha carreira no hospi- 
tal então ali começou uma oportunidade de aprendizado que me ajudou muito durante o percurso para mim e chegar na faculdade e ter um pouco mais de noção, porque eu já estava inserida dentro do processo de trabalho. (E09)

Quando questionamos as enfermeiras quanto às oportunidades de aprendizagem no trabalho durante a trajetória profissional, muitas citam instituições que já trabalharam como referência e a própria faculdade.

\section{Terceiro constructo - Autonomia}

O poder de decisão e a resolutividade de problemas atrelado à autonomia é essencial no trabalho em equipe e no exercer profissional do enfermeiro. As ideias centrais das respostas de algumas enfermeiras entrevistadas relativas à questão 04) "Comente como você vê a sua autonomia no seu trabalho." são descritas abaixo:

[...] tenho autonomia, gosto bastante de trabalhar aqui [...] nos outros trabalhos nem sempre, bem diferente. (E01)

[...] tenho porque eles deixam em aberto pra gente buscar a resolução dos problemas e também passar nosso conhecimento para os funcionários. (E03)

[...] no turno da manhã é que eu convivo desde o início. Tenho mais autonomia da manhã, convivo mais tempo, mas com a turma da tarde não vai ser muito diferente. (E05)

[...] é importante, mas todas (outras profissionais) compreendem que tem uma hierarquia [...] não preciso mandar o que tem que fazer, me respeitam, não tenho problema quanto a isso. (E06) [...]a gente no trabalho a gente é gestor e não chefe [...]a autonomia vem junto com a liderança, da tua atividade, atitude, responsabilidade e acima de tudo junto com o conhecimento técnico científico durante a universidade.

\section{6}

O trabalho em equipe faz parte do cotidiano da Enfermagem e possibilita o contato com diversas áreas da saúde, constituindo um time multiprofissional e interdisciplinar

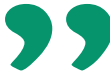

(E09)

A autonomia é o constructo no qual confere ao trabalho a capacidade de deixar uma boa margem de liberdade, de independência e de discrição à pessoa para ela determinar as maneiras de realizá-lo, trazendo consigo o sentimento de responsabilidade pela realização das tarefas, ou seja, o trabalho deve invocar a capacidade de decisão da pessoa (12).

Quarto Constructo - Cooperação e Relacionamento com Colegas

O trabalho em equipe faz parte do cotidiano da Enfermagem e possibilita o contato com diversas áreas da saúde, constituindo um time multiprofissional e interdisciplinar. Diretamente, o Enfermeiro é líder da equipe de Enfermagem, sendo esta constituída por técnicos e auxiliares de Enfermagem. Podemos observar as respostas de algumas profissionais abaixo quanto a pergunta 05) "Como você vivencia a cooperação e o relacionamento com seus colegas de trabalho?"

[...] a Enfermagem é uma área mais complicada de se trabalhar [...]nem sempre a gente encontra flores no caminho, mas eu acho que o trabalho em equipe é que faz o sucesso da coisa. [...] tem que ter um vínculo de respeito. (E02)

[...] excelente, tenho uma equipe muito boa sabe, eles tem um respeito por mim, eu procuro ter um respeito por eles. (E03)

[...] tenho uma boa cooperação porque a maioria dos funcionários já tem um bom tempo de casa. (E05)

[...]um pouco difícil trabalhar em equipe porque cada pessoa tem um jeito diferente, um caráter diferente, uma postura diferente [...] nem sempre no processo de trabalho as coisas acontecem como a gente espera, nunca é perfeito, mas quando a gente trabalha em conjunto e não sozinho, eu acho que o resultado no final é positivo. (E09)

A cooperação e o relacionamento 
com os colegas de trabalho nem sempre se mostram serenos nos depoimentos dos profissionais entrevistados (E02, E09). As relações no trabalho nos permite vivenciar experiências diversas e manter laços sociais e afetivos: são encontros e desencontros na construção da nossa trajetória profissional.

\section{Quinto Constructo - Reconhecimento}

Em relação ao constructo "reconhecimento", observaramse relatos distintos e, nem todas entrevistadas tem seu trabalho reconhecido, seja pela instituição, família, paciente ou outros profissionais. Quanto à pergunta 06) "Qual a sua percepção na questão do reconhecimento do seu trabalho?" são descritas abaixo algumas falas das profissionais:

[...] eu acredito que ainda é bem falho [...]ninguém chega pra você e fala nossa, como seu trabalho tá bom, ninguém faz isso [...]a atitude boa tem que ser reforçada e valorizada [...]faz uma diferença, a pessoa trabalha melhor. (E01)

[...] no geral em instituição nenhuma, eu digo no geral, eu acho que o enfermeiro é pouco reconhecido. (E02)

[...] eu esperava mais, mas hoje eu me conformo com poucos sorrisos e agradecimentos que recebo. (E03)

[...]nem sempre é reconhecido [...] a gente como enfermeiro queria que fosse mais né, gostaria que o salário fosse maior, que tivesse mais benefício, participação no plano de saúde. (E07)

É possível observar através dos depoimentos das enfermeiras que a utilidade social muitas vezes está condicionada ao reconhecimento profissional: o profissional se sente útil quando há uma contrapartida da instituição, do paciente, família

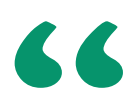

O sentido do trabalho para estas enfermeiras possuíam características polissêmicas. As enfermeiras reconhecem a utilidade social de seus trabalhos no âmbito do cuidado ao paciente, como uma atividade que beneficia aos próximos e que gera um valor agregado

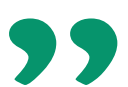

ou equipe em relação ao mérito de seu trabalho.Verificamos posições diferentes das enfermeiras, algumas nem sempre se sentiam reconhecidas (E01, E02, E03, E07).

Sexto Constructo - Retidão moral

As dimensões éticas possuem desdobramentos importantes nas relações interpessoais e no próprio trabalho da Enfermagem. Quando questionadas sobre essas questões no ambiente de trabalho, a estranheza perante a pergunta 07) "Como você vivencia as dimensões éticas no ambiente do seu trabalho?" se fez presente:

[...] é uma questão bem complicada e tem que se trabalhar muito, é fundamental essa educação continuada em cima da parte ética [...] não adianta a gente ter um profissional que saiba todas as técnicas mas que não tem esta parte ética envolvida. (E02)

[...] ainda tem muita coisa a meIhorar, um dos pontos a serem melhorados. (E04)

[...] então esta questão de ética é bem ativa na área da saúde [...] ela precisa ser aplicada a todos os instantes, a todos os momentos. Não é só com o outro né, com o paciente que a gente entende mas com o colega de trabalho também. Porque ser ético é você estar sozinho e tu saber que está fazendo algo errado e tu não faz, porque tu sabe que está errado. (E09)

Na sua unanimidade, as enfermeiras relatam a falta de ética por parte de alguns profissionais: A dimensão ética na construção dos sentidos do trabalho é uma atividade que se inscreve no desenvolvimento de uma sociedade.

\section{CONCLUSÃO}

Utilizando-se os seis constructos 
dos sentidos do trabalho (utilidade social; oportunidades de aprendizagem e desenvolvimento; autonomia; cooperação e relacionamento com colegas; reconhecimento $\mathrm{e}$; retidão moral) nove enfermeiras com diferentes trajetórias profissionais e pessoais foram entrevistadas neste estudo. Os relatos das profissionais revelam que, muitas delas iniciaram sua experiência na Enfermagem através de um curso técnico para, posteriormente, graduarem-se no Ensino Superior.

O sentido do trabalho para estas enfermeiras possuíam características polissêmicas. As enfermeiras reconhecem a utilidade social de seus trabalhos no âmbito do cuidado ao paciente, como uma atividade que beneficia aos próximos e que gera um valor agregado. As oportunidades de aprendizado e desenvolvimento é o constructo intimamente ligado às experiências do dia a dia e revelam que as mesmas possuíam interesse em desenvolver novas habilidades que poderiam ser aplicadas em suas rotinas de seus trabalhos e, as entrevistadas demonstraram interesse nos desafios relacionados a este constructo. Em relação à autonomia, as enfermeiras conseguem exercer seu trabalho com este princípio em sua integralidade, apesar de muitas trabalharem há menos de seis meses na instituição.

O constructo da cooperação e relacionamento com os colegas evidenciou uma vivência no trabalho permeada por dificuldades em lidar com as pessoas da equipe, em virtude de diferentes posturas assumidas. Entretanto, as enfermeiras reconhecem que o trabalho multiprofissional e o vínculo harmônico entre todos são essenciais no desenvolvimento do trabalho na área da saúde. Em relação ao reconhecimento, tivemos relatos diferentes, onde nem todas tem seu trabalho reconhecido, seja pela instituição, pela família, paciente ou outros profissionais. Muitas das dificuldades relatadas relacionam-se com os constructos de dimensões éticas no trabalho. A preocupação pela falta de respaldo ético em certas atividades e/ou posturas assumidas do dia a dia por parte de alguns profissionais se fizeram presente nas falas.

Encerramos esta pesquisa deixando como proposta intencional a exploração dos sentidos do trabalho em novos cenários na área da Enfermagem: das unidades básicas de saúde aos setores de alta complexidade hospitalar; da docência nas universidades aos cursos técnicos, como forma de manter acesas estas reflexões que trazem a essência do cuidado à profissão.

\section{Referências}

1 Brasil. Lei No 7.498, de 25 de Junho de 1986. Dispõe sobre a regulamentação do exercício da enfermagem, e dá outras providências. Brasília;1986.

2 Antunes A. Os sentidos do trabalho: Ensaio sobre a afirmação e a negação do trabalho. Coimbra: CES/Almedina; 2013.

3 Tolfo SR, Piccinini Valmíria. Sentidos e significados do trabalho: explorando conceitos, variáveis e estudos empíricos brasileiros. Psicol. Soc. [online]. 2007, 19:pp.38-46. doi: https://doi.org/10.1590/S010271822007000400007.

4 Sá JGS, Lemos AHC. Sentido do Trabalho: Análise da Produção Científica Brasileira. Revista ADM.MADE.2017, 21(3):21-39. doi: http://dx.doi. org/10.21714/2237-51392017v21n3p021039

5 Rodrigues AL, Barrichello A, Morin E. Os sentidos do trabalho para profissionais de enfermagem: um estudo multimétodos. Rev. adm. empres. 2016, 56 (2). doi: https://doi.org/10.1590/S0034-759020160206

6 Schweitzer L, Goncalves J, Tolfo SR, Silva N. Bases epistemológicas sobre sentido(s) e significado(s) do trabalho em estudos nacionais. Rev. Psi: Org e Trab R. Eletr. Psico. 2016, 16(1):103-116.

7 Quintanilha FS. Programa de educação permanente e desenvolvimento organizacional e profissional de enfermagem no Hospital Universitário Onofre Lopes (HUOL) [dissertação]. João Pessoa (PB): Universidade Fede- ral da Paraíba; 2014.

8 Conselho Federal de Enfermagem, Fundação Osvaldo Cruz. Pesquisa Perfil da Enfermagem no Brasil. Brasília: 2013.

9 Reisdorfer AP. Programa de Educação Permanente em Saúde para a equipe de Enfermagem da UTI adulto: cuidado ao paciente no pós operatório de cirurgia cardíaca [dissertação]. Porto Alegre (RS): Universidade do Vale do Rio dos Sinos; 2016.

10 Lima JHV, Ésther AB. Transições, prazer e dor no trabalho de enfermagem. Rev. adm. Empres. 2001 41(3):20-30. doi: https://doi.org/10.1590/ S0034-75902001000300003

11 Instituto Brasileiro de Geografia e Estatística. Síntese de indicadores sociais: uma análise das condições de vida da população brasileira. Rio de Janeiro; 2016.

12 Morin E. Os sentidos do trabalho. Rev. adm. Empres. 2001, 41(3):8-19. doi: https://doi.org/10.1590/S0034-75902001000300002.

13 Pereira EF. Sentidos do trabalho para servidores públicos federais afastados do ambiente laboral por estresse [dissertação]. Florianópolis (SC): Universidade Federal de Santa Catarina; 2014.

14 Morin E, Tonelli MJ, Pliopas ALV. 0 trabalho e seus sentidos. Psicol. soc. (Online). 2007, 19(1): 47-56. doi: https://doi.org/10.1590/S010271822007000400008 . 